\title{
Severe Dengue Virus Infection in Travelers: Risk Factors and Laboratory Indicators
}

\author{
Ole Wichmann, ${ }^{1,3}$ Joaquim Gascon, ${ }^{7}$ Mirjam Schunk, ${ }^{4}$ Sabino Puente, ${ }^{8}$ Heli Siikamaki, ${ }^{11}$ Ida Gjørup, ${ }^{12}$ \\ Rogelio Lopez-Velez, ${ }^{9}$ Joannes Clerinx, ${ }^{13}$ Gabriele Peyerl-Hoffmann, ${ }^{5}$ Anders Sundøy, ${ }^{14}$ Blaise Genton, ${ }^{15}$ Peter Kern, ${ }^{6}$ \\ Guido Calleri, ${ }^{16}$ Miguel de Górgolas, ${ }^{10}$ Nikolai Mühlberger, ${ }^{2}$ and Tomas Jelinek, ${ }^{2}$ for the European Network \\ on Surveillance of Imported Infectious Diseases \\ ${ }^{1}$ Institute of Tropical Medicine, Charité University Medicine, ${ }^{2}$ Berlin Center for Travel and Tropical Medicine, and ${ }^{3}$ Department for Infectious \\ Disease Epidemiology, Robert Koch Institute, Berlin; ${ }^{4}$ Department of Infectious Diseases and Tropical Medicine, University of Munich, Munich, \\ ${ }^{5}$ Infectious Disease Clinic, Abteilung Innere Medizin II, University of Freiburg, Freiburg, and ${ }^{6}$ Sektion Infektiologie und Klinische Immunologie, University \\ of Ulm, Ulm, Germany; ${ }^{7}$ Centre Salut Internacional, Institut d'Investigacions Biomèdiques August Pi i Sunyer, Hospital Clinic Barcelona, \\ and ${ }^{8}$ Department of Infectious Diseases and Tropical Medicine, Hospital Carlos III, ${ }^{9}$ Tropical Medicine and Clinical Parasitology Unit, Infectious

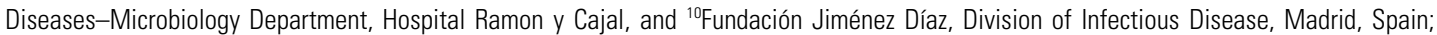 \\ ${ }^{11}$ Helsinki University Central Hospital, Department of Medicine, Division of Infectious Diseases, Helsinki, Finland; ${ }^{2}$ Rigshospitalet Copenhagen, \\ University of Copenhagen, Denmark; ${ }^{13}$ Prins Leopold Instituut voor Tropische Geneskunde, Clinical Services, Antwerp, Belgium; ${ }^{14}$ Sorlandet \\ Hospital, Kristiansand, Norway; ${ }^{15}$ Travel Clinic at the Policlinique Médicale Universitaire, University of Lausanne, Lausanne, Switzerland; ${ }^{16}$ Division \\ "A" Malattie Infettive, Ospedale Amedeo di Savoia, Torino, Italy
}

\section{(See the editorial commentary by Wilder-Smith and Tambyah, on pages 1081-3.)}

Background. Dengue fever is the most common arboviral disease in travelers. In countries where dengue virus is endemic, sequential (secondary) infections with different dengue virus serotypes are associated with disease severity. Data on severity and secondary infection rates in a population of travelers are lacking.

Methods. Intensified surveillance of dengue fever in travelers was performed within the European Network on Surveillance of Imported Infectious Diseases. Data were collected at 14 European clinical referral centers between 2003 and 2005.

Results. A total of 219 dengue virus infections imported from various regions of endemicity were reported. Serological analysis revealed a secondary immune response in 17\%. Spontaneous bleeding was observed in 17 $(8 \%)$ patients and was associated with increased serum alanine and aspartate aminotransferase levels and lower median platelet counts. Two $(0.9 \%)$ patients fulfilled the World Health Organization (WHO) case definition for dengue hemorrhagic fever. However, 23 (11\%) travelers had severe clinical manifestations (internal hemorrhage, plasma leakage, shock, or marked thrombocytopenia). A secondary immune response was significantly associated with both spontaneous bleeding and other severe clinical manifestations.

Conclusions. In travelers, severe dengue virus infections are not uncommon but may be missed if the WHO classification is strictly applied. High liver enzyme levels and low platelet counts could serve as indicators of disease severity.

Dengue fever is increasingly recognized to be the most important arboviral infection in travelers [1]. Among

Received 30 June 2006; accepted 26 September 2006; electronically published 2 March 2007

Potential conflicts of interest: none reported.

Presented in part: 9th Conference of the International Society of Travel Medicine, Lisbon, 1-5 May 2005 (poster 06.22).

Financial support: Society for Tropical and Travel Medicine

Reprints or correspondence: Dr. Ole Wichmann, Robert Koch Institute, Dept. for Infectious Disease Epidemiology, Seestr. 10, 13353 Berlin, Germany (Wichmann0@ rki.de).

The Journal of Infectious Diseases 2007; 195:1089-96

(c) 2007 by the Infectious Diseases Society of America. All rights reserved. 0022-1899/2007/19508-0004\$15.00

DOI: $10.1086 / 512680$
17,353 ill travelers reported in the surveillance network GeoSentinel, dengue virus infection was, in travelers with specific diagnoses, the leading cause of febrile illness for every geographic region except sub-Saharan Africa and Central America [2]. With a 30-fold growth in incidence over the past 50 years worldwide, the disease has expanded its geographical distribution to almost all tropical and subtropical countries [3, 4]. Recently, the virus has spread to the Middle East [5] and the US states of Hawaii and Texas $[6,7]$. At the same time, the activity of international air travel is continuously increasing. According to the World Tourism Organization, the number of international tourist arrivals recorded worldwide in 2005 was $>800$ million persons 
for the first time ever [8]. Therefore, health care providers in industrialized countries should have an understanding of the clinical spectrum of the disease and its diagnosis when managing returning travelers.

As in populations living in areas of endemicity, most dengue virus infections in travelers are asymptomatic [9]. The manifestations of symptomatic disease range, however, from mild febrile illness to a severe form with clinical bleeding and shock caused by plasma leakage (dengue hemorrhagic fever [DHF]). The exact mechanism of enhanced severity is not fully understood, but secondary dengue virus infection, defined as sequential infection with 2 of the 4 heterologous serotypes (DEN$1,-2,-3$, and -4$)$, is thought to be the main factor $[10,11]$. Differences in viral virulence and host characteristics (genetic dispositions or underlying diseases) seem to play an important role as well $[12,13]$.

Infection with one dengue virus serotype confers lifelong immunity to that specific serotype but leads only to a few months of cross-immunity that protects from disease caused by 1 of the other 3 dengue virus serotypes [4]. This temporary cross-immunity might explain to some extent why DHF is rarely seen in travelers. Nonetheless, fatal dengue associated with fulminant hepatic failure [14] or subarachnoidal hemorrhage [15] have recently been reported in travelers. Severe manifestations of dengue virus infection, such as encephalitis [16] or visual loss [17], have also been reported in returning travelers in recent years. Severe postdengue depression has been described in a Spanish traveler that resulted in suicide [18].

In travelers, our knowledge about severe dengue manifestations is mainly based on published single case reports. Reliable data on disease severity and on clinical and laboratory features of dengue virus infection are uncommon [1, 19-22]. In particular, the impact on morbidity and mortality of secondary dengue virus infections in travelers has not been correctly estimated.

\section{PATIENTS, MATERIALS, AND METHODS}

The present study was established within the infrastructure of the European Network on Surveillance of Imported Infectious Diseases (TropNetEurop) [22]. Sentinel surveillance reporting is currently performed by 51 participating clinical sites throughout 17 European countries using a standardized and computerized reporting system. All member sites are large referral centers for tropical or travel medicine, where $\sim 63,000$ patients annually present spontaneously or are referred with symptoms after travel.

Since May 2003, surveillance has been intensified by use of an additional standardized questionnaire covering dengue-specific issues: dengue-related symptoms, serological results, hematological values, chemical constituents of the blood, history of previous travel, and immunizations. Anonymous data col- lected from patients with dengue virus infection who presented spontaneously or by referral between May 2003 and December 2005 at 1 of 14 participating clinical sites of the network were sent to the coordination center in Berlin.

According to the World Health Organization (WHO) [23], reported patients were classified into 2 categories: patients with probable and those with confirmed dengue virus infection. For confirmation, the virus was detected by reverse-transcriptase polymerase chain reaction (RT-PCR) or by a significant change in IgM or IgG antibody titers in paired serum samples. A probable diagnosis of dengue virus infection was supported by a single positive IgM antibody test on a late acute- or convalescent-phase serum specimen (i.e., 4-7 or 8-45 days, respectively, after the onset of symptoms). The serological analysis was performed at the clinical sites, which are all specialized centers. In cases where an ELISA kit was used and both IgM and IgG quantitative test results were available, the evaluation of patients' immune response was performed in accordance with the manufacturer's instructions. For the most commonly used combination of PanBio IgM capture ELISA and IgG indirect ELISA (PanBio), a secondary immune response was defined as having a sample:calibrator absorbance ratio for IgG of $\geqslant 4$ in the presence of an IgM ratio of $\geqslant 1$. For RT-PCR analysis, either center-specific in-house test kits were used or (most often) samples were sent to a reference center where RT-PCR was performed as described elsewhere [24].

The WHO clinical case definition for DHF was applied and required the presence of all 4 criteria: fever, platelet count $<100,000$ cells $/ \mathrm{mm}^{3}$, hemorrhagic tendency, and evidence of capillary leakage (i.e., hematocrit increase of $\geqslant 20 \%$ from baseline, pleural effusion, ascites, or hypoproteinemia) [23]. Hemorrhagic tendency was defined as spontaneous bleeding or signs of capillary fragility [23]. Spontaneous bleeding was evidenced as bleeding from the nose, gums, or gastrointestinal (GI) tract or hypermenorrhea or ecchymosis. Petechiae and a positive tourniquet test were considered to be signs of capillary fragility.

As used in previous publications $[25,26]$, severe clinical manifestations were defined as internal hemorrhage, plasma leakage, shock (i.e., hypotension for age or pulse pressure $\leqslant 20$ $\mathrm{mm} \mathrm{Hg}$ ), and/or a platelet count $\leqslant 50,000$ cells $/ \mathrm{mm}^{3}$. Internal hemorrhage consisted of GI-tract bleeding and/or hypermenorrhea. Leukopenia was defined as a white blood cell (WBC) count $\leqslant 4500$ cells $/ \mathrm{mm}^{3}$ and thrombocytopenia as a platelet count $\leqslant 150,000$ cells $/ \mathrm{mm}^{3}$. The increase in aspartate aminotransferase (AST) and alanine aminotransferase (ALT) levels was graded in accordance with the normal values of each member site's laboratory. For the analysis of laboratory features, only patients who presented during the acute phase (i.e., $\leqslant 10$ days after the onset of symptoms) of illness were included.

All data were entered into a Microsoft Access database (Microsoft Access 2002; Microsoft) and exported to SPSS software 
(version 13.0 for Windows; SPSS). Groups with and without specific presentations were compared by $\chi^{2}$ tests. A statistically significant difference was determined by $P<.05$. For multivariate analysis, logistic regression models were applied using stepwise backward removal with the inclusion of age, sex, and all variables that had $P \leqslant .1$ in univariate analysis in the first step. Crude odds ratios and their Cornfield 95\% confidence intervals were calculated.

\section{RESULTS}

Patients' characteristics and travel history. During the study period, a total of 219 patients (109 male and 110 female) with acute or recent dengue virus infections were reported (median age, 32 years; range, 11-70 years). Most patients (90\%) were European, and $17(8 \%)$ were of non-European origin but were living in $(n=15)$ or visiting $(n=2)$ Europe (information was missing for 6 patients). All patients of non-European origin were born in countries where dengue is endemic. Nearly all patients acquired the dengue virus infection either in Southeast Asia $(n=77[35 \%])$, the Indian subcontinent $(n=63[29 \%])$, or the Americas $(n=62[28 \%])$ (table 1). Among patients who visited 1 country only, India $(n=43[23 \%])$, Thailand $(n=31[17 \%])$, and Sri Lanka $(n=15[8 \%])$ topped the list of 39 countries. The median duration of travel was 24 days (range, 4 days -4 years). For 39\%, it was their first visit to a country where dengue is endemic, whereas $61 \%$ had made previous visits (1-3 times, 37\%; $>3$ times, $24 \%$ ). Six patients $(2.7 \%)$ had a history of documented dengue virus infection in the past.

Diagnosis of dengue virus infection and patients' immune response. Dengue virus infection was confirmed in 133 patients $(61 \%)$ and was diagnosed as probable in the remaining 86 (39\%). Confirmation was achieved in 115 cases by increasing dengue antibody titers in paired serum samples, in 2 by PCR only, and in 16 by combining both methods. A probable diagnosis was established in 86 patients with at least a positive IgM antibody titer in a single serum sample (57 had a positive IgG result as well). For serological analysis, most often ( $n=$ $174[79 \%])$ the commercially available PanBio-ELISA was used to detect both IgM and IgG antibodies. There was no significant difference in the frequency of clinical, laboratory, or demographic characteristics between the population with probable and confirmed dengue virus infection.

Serological analysis indicated a primary immune response in 134 patients $(77 \%)$ and a secondary immune response in 40 patients $(23 \%)$. In 45 cases ( 37 probable and 8 confirmed infections), the discrimination was not possible because of missing quantitative IgM or IgG levels. Thirteen patients with a secondary immune response were excluded from the analysis because of a history of flavivirus immunization (11 against yellow fever, 2 against tickborne encephalitis, and 0 against
Japanese encephalitis). Thus, 27 patients (17\%) were regarded as having acquired a secondary dengue virus infection. Europeans were significantly less likely to exhibit a secondary immune response than were persons of non-European origin (14\% vs. $50 \% ; P=.001$ ).

Clinical and hematological features. Clinical manifestations associated with dengue virus infection are presented in table 2. Petechiae occurred in 28 patients (13\%) and spontaneous bleeding in 17 patients $(8 \%)$. Spontaneous bleeding presented most often as bleeding from the nose or gum. One patient developed GI-tract bleeding presenting as hematemesis.

At 4 study sites, a tourniquet test was applied in a total of 82 patients, with $36(44 \%)$ showing a positive test result. A positive test was associated with the occurrence of petechiae ( $42 \%$ vs. $2 \% ; P<.001)$ but not with spontaneous bleeding $(24 \%$ vs. $8 \% ; P=.1)$. Furthermore, there was no significant association between a positive test and the frequency of severe clinical manifestation ( $21 \%$ vs. $5 \% ; P=.07)$, a platelet count $<100,000$ cells $/ \mathrm{mm}^{3}(P=.59)$, being of non-European origin $(P=.4)$, secondary immune response $(P=.3)$, or a $>3$-fold increased AST level $(P=.3)$. A $>3$-fold increased ALT level was associated with a positive test result $(P=.02)$. There was no difference in the median duration of symptoms before the test was applied (positive/negative result, 5 vs. 4 days; $P=.9$ ).

As shown in table 3, most patients had either a low WBC or platelet count during the acute phase of illness. Eighteen patients $(10 \%)$ had marked thrombocytopenia with a platelet count $<50,000$ cells $/ \mathrm{mm}^{3}$, and 2 patients (1\%) had counts $<20,000$ cells $/ \mathrm{mm}^{3}$. Among those patients tested, more than half had increased liver enzyme levels. Table 3 shows the most abnormal values observed in each patient over the course of the disease, demonstrating that most abnormal WBC or platelet

\section{Table 1. Geographic regions in which 219 travelers acquired a dengue virus infection (2003-2005).}

\begin{tabular}{lc}
\hline Region, country & $\begin{array}{c}\text { Subjects with } \\
\text { dengue, no. (\%) }\end{array}$ \\
\hline Asia & $77(35.2)$ \\
Southeast Asia & $63(28.8)$ \\
Indian subcontinent & $1(0.5)$ \\
Rest of Asia & \\
The Americas & $39(17.8)$ \\
Central America & $16(7.3)$ \\
South America & $7(3.2)$ \\
Caribbean & \\
Africa & $2(0.9)$ \\
Central Africa & $10(4.6)$ \\
East Africa & $2(0.9)$ \\
West Africa & $2(0.9)$ \\
South Africa & $219(100)$ \\
$\quad$ Total &
\end{tabular}


Table 2. Clinical presentations of dengue in 219 travelers (multiple entries possible).

\begin{tabular}{|c|c|}
\hline Symptom & $\begin{array}{c}\text { Subjects } \\
\text { presenting, no. (\%) }\end{array}$ \\
\hline Fever & 203 (92.7) \\
\hline Headache & 152 (69.4) \\
\hline Fatigue & $124(56.6)$ \\
\hline Rash & $116(53.0)$ \\
\hline Muscle pain & 109 (49.8) \\
\hline Retroorbital pain & $96(43.8)$ \\
\hline Hemorrhagic tendencies $^{a}$ & $57(26.0)$ \\
\hline Tourniquet test ${ }^{\mathrm{b}}$ & $36(43.9)$ \\
\hline Petechiae & $28(12.8)$ \\
\hline Spontaneous bleeding & $17(7.8)$ \\
\hline Epistaxis & $6(2.7)$ \\
\hline Gum bleeding & $5(2.3)$ \\
\hline Hypermenorrhea $^{c}$ & $3(2.7)$ \\
\hline Ecchymosis & $4(1.8)$ \\
\hline Gl-tract bleeding & $1(0.5)$ \\
\hline Diarrhea & $54(24.7)$ \\
\hline Pruritus & $46(21.0)$ \\
\hline Change in taste & $32(14.6)$ \\
\hline Vomiting & $29(13.2)$ \\
\hline Splenomegaly & $9(4.1)$ \\
\hline Lymphadenopathy & $8(3.7)$ \\
\hline Neuropsychological symptoms & $7(3.2)$ \\
\hline Hypotension for age & $1(0.5)$ \\
\hline
\end{tabular}

values were found between 3 and 6 days after the onset of symptoms, whereas most abnormal AST, ALT, or lactate dehydrogenase values were often found later. Table 4 shows laboratory features in patient groups with different clinical presentations and trends of platelet counts, liver enzyme levels, and frequencies of secondary dengue virus infections.

Only $2(0.9 \%)$ patients fulfilled the WHO clinical case definition for DHF-both had evidence of hemoconcentration, with hematocrit increasing by $\geqslant 20 \%$ over the course of the disease, in addition to fever, hemorrhagic tendencies, and a platelet count $<100,000$ cells $/ \mathrm{mm}^{3}$. Serological analysis was compatible with a primary infection in 1 patient and with a secondary infection in the other. Neither developed signs of shock.

Associations with spontaneous bleeding. A total of $17 \mathrm{pa}-$ tients $(8 \%)$ had spontaneous bleeding that was associated with secondary immune response, with non-European origin and with a $>3$-fold increased serum ALT level in multivariate analysis (table 5). The median platelet count in patients with spontaneous bleeding was 72,000 cells $/ \mathrm{mm}^{3}$ (range, $17,000-349,000$ cells $\left./ \mathrm{mm}^{3}\right)$; that in patients without spontaneous bleeding was 110,000 cells $/ \mathrm{mm}^{3}(P=.06)$.

Associations with severe clinical manifestations. A total of 23 patients (11\%) demonstrated manifestations of severe dengue disease (internal hemorrhage, 4; plasma leakage, 2; shock, 1 ; and platelet count $\leqslant 50,000$ cells $/ \mathrm{mm}^{3}, 18$ ). In multivariate analysis, secondary immune response and a $>3$-fold increased serum AST level were the only independent predictors of severe manifestations (table 5). There was no association between severe dengue disease and the median duration of travel abroad ( 21 vs. 25 days; $P=.5$ ). Eight patients $(34 \%)$ with severe clinical manifestations and $5(29 \%)$ with spontaneous bleeding had visited a dengue-endemic country the first time.

Other complications and hospitalization rate. A total of 51 patients $(23 \%)$ required hospitalization because of complications or aggravation of dengue-related symptoms. The medium duration of hospitalization was 4 days (range, 1-11 days). A 60-year-old patient with spontaneous bleeding required treatment at an intensive care unit because of atrial fibrillations during the acute phase of illness (first time with no history of underlining cardiac disease; after recovery, there were normal findings in stress echocardiography and scintigraphy). One patient complained of blurred vision with black dots in the vision field of both eyes (which disappeared gradually over the course of 2 months without sequelae), and 1 patient presented with hypotension for age.

\section{DISCUSSION}

In many European countries, notification of imported dengue virus infections is not mandatory. Therefore, only few publications are available describing large populations of travelers with dengue virus infection [19-22, 27, 28]. Most of these focused on epidemiological or basic clinical data only. Here, we present more complete clinical and hematological data collected from $>200$ dengue virus-infected travelers, as well as estimates on the rate of secondary (sequential) infections and the usefulness of the tourniquet test in a population of travelers.

The diagnostic value of the tourniquet test was recently evaluated in a large study among 905 Vietnamese children; positive results were found in only $42 \%$ of dengue virus-infected patients [29]. The test was regarded to be a cheap and simple clinical method that is suggestive of dengue when positive, but a negative test does not exclude the disease. In our population of international travelers, the sensitivity of the test was relatively low at $44 \%$, as in the Vietnamese study. The sensitivity of the test can be improved by repeated testing, but this was not performed in many cases, because most patients presented to outpatient departments. In our population, a positive test was not associated with lower platelet counts or spontaneous bleeding. This has also been seen in Thai patients with dengue [30] and is a direct consequence of the fact that the tourniquet test 
Table 3. Laboratory features in 176 travelers with dengue fever presenting during the acute phase of illness ( $\leqslant 10$ days after the onset of symptoms).

\begin{tabular}{|c|c|c|c|c|}
\hline \multirow[b]{2}{*}{ Laboratory feature } & \multirow[b]{2}{*}{ All } & \multicolumn{3}{|c|}{$\begin{array}{l}\text { Days after onset of } \\
\text { symptoms }\end{array}$} \\
\hline & & $0-2$ & $3-6$ & $7-10$ \\
\hline Leukopenia $\left(<4500\right.$ cells $\left./ \mathrm{mm}^{3}\right)$ & $130(74)$ & $16(69)$ & $96(85)$ & $18(60)$ \\
\hline Thrombocytopenia $\left(<150,000\right.$ cells $\left./ \mathrm{mm}^{3}\right)$ & $123(71)$ & $10(53)$ & $80(76)$ & $33(70)$ \\
\hline Leuko- and thrombocytopenia & $104(60)$ & $12(52)$ & $76(67)$ & $16(53)$ \\
\hline Marked thrombocytopenia $\left(<50,000\right.$ cells $\left./ \mathrm{mm}^{3}\right)$ & $18(10)$ & $1(5)$ & $11(11)$ & $6(13)$ \\
\hline \multicolumn{5}{|l|}{ AST $(n=149)$} \\
\hline Mild increase (<3-fold) & $58(34)$ & $6(40)$ & $27(43)$ & 22 (33) \\
\hline Moderate increase (3-5-fold) & $25(17)$ & 0 & $12(19)$ & 12 (18) \\
\hline Severe increase (>5-fold) & $18(12)$ & 0 & $5(8)$ & 13 (19) \\
\hline \multicolumn{5}{|l|}{$\operatorname{ALT}(n=165)$} \\
\hline Mild increase (<3-fold) & $59(36)$ & $2(12)$ & $20(35)$ & $18(30)$ \\
\hline Moderate increase (3-5-fold) & $18(11)$ & 0 & $8(14)$ & $6(10)$ \\
\hline Severe increase (>5-fold) & $21(13)$ & 0 & $2(3)$ & $14(23)$ \\
\hline LDH increase $(n=104)$ & $70(67)$ & $6(50)$ & $31(65)$ & $21(72)$ \\
\hline
\end{tabular}

NOTE. Data are no. (\%) of subjects. The most abnormal values observed over the course of illness are presented stratified by time after onset of symptoms. In several cases, the most abnormal value for serum aspartate aminotransferase (AST), serum alanine aminotransferase (ALT), and lactate dehydrogenase (LDH) were observed $>10$ days after the onset of symptoms.

measures capillary fragility rather than a tendency toward systemic bleeding. By contrast, a positive test result was associated with the presence of petechiae, which can also be regarded as a sign of capillary fragility. Most important, the test cannot be used to predict spontaneous bleeding or to distinguish between severe and nonsevere disease.

ELISAs [31] can be used to classify dengue virus infection as primary or secondary by determining the ratio of units of dengue IgM:IgG antibody titers. High IgG levels are indicative of secondary infections. Vaughn et al. [32] demonstrated, with a panel of 78 dengue samples, that the PanBio-ELISA was able to classify $100 \%$ of the primary and $96 \%$ of the secondary infections correctly when a cutoff value of 3.0 was applied. However, previous immunization against other flaviviruses may render the IgG ELISA test less specific because of cross-reaction [33]. Therefore, we chose a cutoff value of 4.0, as recommended by the manufacturer, and we excluded patients with previous immunizations against other flaviviruses from the analysis of the immune response. Even then, 27 travelers (17\%) demonstrated an antibody immune response indicative of secondary dengue virus infection. Furthermore, previously acquired flavivirus infections other than dengue could have resulted in a positive IgG response. The very low incidence of yellow fever and Japanese encephalitis in travelers, however, suggests that cross-reactivity with antibodies from other flavivirus infections was negligible in the present study. In our population, the relatively high proportion of travelers with secondary dengue virus infections is a reflection of the fact that $61 \%$ had traveled to a dengue-endemic country before. It can be suggested that, of the millions of people traveling every year to areas where dengue is endemic [8], a considerable proportion will have visited these areas more than once, too.

Of 77 patients diagnosed with dengue in the United States between 2001 and 2004, $8(10 \%)$ had a primary infection and $12(16 \%)$ had a secondary infection (for the remaining 57 patients, the distinction was not able to be determined) [21]. In this population, the majority of travelers reported recent travel to a Caribbean island (30\%), to a Pacific island $(21 \%)$, or to Asia (17\%). These figures reflect travel habits, as they do in our study population, that consisted mainly of Europeans traveling for tourism to Southeast Asia, the Indian subcontinent, and the Americas. From all of the hitherto published series, the data collected within TropNetEurop are probably the most representative for European travelers, given that 14 major referral centers from 8 different countries of the continent participated in the surveillance.

In the present study, a few unusual clinical observations associated with dengue virus infection were made. One patient presented with dengue disease complicated by blurred vision, and another patient had acute atrial fibrillation. Ophthalmic complications have been described in the literature [34], whereas cardiac complications are rare and manifest usually as myocarditis [35]. Our patient did not have signs of myocarditis in laboratory or echocardiological examinations. Obviously, it cannot be proved whether atrial fibrillation was directly caused by the dengue virus infection or was instead triggered by a febrile stress. There is only one other published case of a patient with dengue disease developing acute atrial fibrillation [36]. 
Table 4. Laboratory features in 176 travelers with dengue fever presenting during the acute phase of illness $(\leqslant 10$ days after the onset of symptoms), classified by bleeding category and the presence of severe clinical manifestations (the most abnormal value in each patient is shown).

\begin{tabular}{|c|c|c|c|c|c|}
\hline \multirow[b]{2}{*}{ Laboratory feature } & \multicolumn{3}{|c|}{ Bleeding category } & \multicolumn{2}{|c|}{ Clinical severity category } \\
\hline & $\begin{array}{c}\text { No hemorrhagic } \\
\text { tendency } \\
(n=121)\end{array}$ & $\begin{array}{l}\text { Petechiae or } \\
\text { positive TT only } \\
(n=38)\end{array}$ & $\begin{array}{c}\text { Spontaneous } \\
\text { bleeding } \\
(n=17)\end{array}$ & $\begin{array}{l}\text { No severe } \\
\text { manifestations } \\
(n=154)\end{array}$ & $\begin{array}{c}\text { Severe }^{a} \\
\text { manifestations } \\
(n=22)\end{array}$ \\
\hline $\mathrm{HCT}$, mean $\pm \mathrm{SD}, \%$ & $42.5 \pm 5.5$ & $43.2 \pm 4.5$ & $42.8 \pm 3.3$ & $42.6 \pm 5.3$ & $43.2 \pm 4.1$ \\
\hline WBC count, cells $/ \mathrm{mm}^{3}$ & $3.2(1.1-10.6)$ & $2.6^{\mathrm{b}}(1.0-6.7)$ & $3.2(1.5-5.6)$ & $3.1(1.0-10.6)$ & $2.4^{\mathrm{C}}(1.4-5.6)$ \\
\hline Platelet count, cells $/ \mathrm{mm}^{3}$ & $120(25-369)$ & $93(18-228)$ & $72^{b}(17-349)$ & $121(17-349)$ & $40^{c}(17-349)$ \\
\hline$A L T, U / L$ & $56(10-695)$ & $70(6-502)$ & $159^{b}(11-448)$ & $56(6-595)$ & $87^{\mathrm{C}}(35-695)$ \\
\hline AST, U/L & $56(10-695)$ & $72(12-564)$ & $115^{\mathrm{b}}(14-442)$ & $55(12-695)$ & $129^{c}(30-588)$ \\
\hline Secondary immune response, \% & 11 & 21 & $46^{\mathrm{b}}$ & 13 & $44^{c}$ \\
\hline
\end{tabular}

NOTE. Data are median (range) values, unless otherwise indicated. ALT, serum alanine aminotransferase; AST, serum aspartate aminotransferase, HCT, hematocrit; TT, tourniquet test; WBC, white blood cell.

a Defined as the presence of internal hemorrhage, signs of plasma leakage, shock, and/or a platelet count $\leqslant 50,000$ cells $/ \mathrm{mm}^{3}$.

b Significant difference vs. patients without hemorrhagic tendency $(P<.05)$.

${ }^{c}$ Significant difference vs. patients without severe manifestations $(P<.05)$.

Underlying chronic diseases, which are likely to be more prevalent in a population of adult travelers than in the children usually affected in countries where dengue is endemic, may cause or mimic "unusual" dengue manifestations.

In areas of endemicity, $\sim 6 \%$ of symptomatic dengue virus infections lead to DHF [37]. In our population, only $0.9 \%$ of travelers with symptomatic disease fulfilled the WHO case definition for DHF, probably because of the comparatively lower prevalence of preexisting dengue antibodies among Europeans. Nonetheless, in recent years, the validity of the WHO classification scheme to define severe dengue disease, which is based on studies of children in Southeast Asia in the 1960s, has been put in doubt [25, 38-41]. Balmaseda et al. [25] found that, especially in adults, the WHO classification is difficult to apply, with many severe cases being missed: more than two-thirds of all adults with severe dengue manifestations were not classified as having DHF. Although shock and plasma leakage seem to be more prevalent as age decreases, the frequency of internal hemorrhage augments as age increases [26]. On the basis of these findings, some authors have raised the question whether DHF represents an entirely separate physiopathological mechanism or whether it reflects only the extreme end of a gradual systemic deterioration triggered by dengue [38]. The relatively low proportion of patients $(8 \%)$ with spontaneous bleeding (including 4 with internal hemorrhage and only 3 with plasma leakage or shock) and the high proportion of marked thrombocytopenia and of capillary fragility observed in the present study support the latter view. In addition, the more arbitrary platelet threshold of 100,000 cells $/ \mathrm{mm}^{3}$, which is integrated into the WHO case definition, failed to predict spontaneous bleed-

Table 5. Laboratory values and other factors associated with spontaneous bleeding and other severe clinical manifestations in 176 travelers with dengue virus infections.

\begin{tabular}{|c|c|c|c|c|}
\hline \multirow[b]{2}{*}{ Factor } & \multicolumn{2}{|c|}{ Spontaneous bleeding $^{\mathrm{a}}(n=17)$} & \multicolumn{2}{|c|}{ Severe clinical manifestations ${ }^{\mathrm{b}}(n=22)$} \\
\hline & $\begin{array}{c}\text { Univariate analysis, } \\
\text { OR }(95 \% \mathrm{CI})\end{array}$ & $\begin{array}{c}\text { Multivariate analysis, } \\
\text { OR }(95 \% \mathrm{Cl})\end{array}$ & $\begin{array}{c}\text { Univariate analysis, } \\
\text { OR }(95 \% \mathrm{Cl})\end{array}$ & $\begin{array}{c}\text { Multivariate analysis, } \\
\text { OR }(95 \% \mathrm{Cl})\end{array}$ \\
\hline $\begin{array}{l}\text { Low platelet count } \\
\qquad\left(<100,000 \text { cells } / \mathrm{mm}^{3}\right)\end{array}$ & $3.1(0.95-10.7)$ & NS & & \\
\hline AST increase (>3-fold) & $3.5(1.1-11.4)$ & NS & $3.5(1.2-10.0)$ & $3.7(1.1-12.6)$ \\
\hline ALT increase (>3-fold) & $3.3(1.1-10.4)$ & $5.4(1.3-21.3)$ & $1.7(0.6-5.1)$ & NS \\
\hline Non-European origin & $3.7(0.9-15.2)$ & $6.4(1.3-32.3)$ & $3.8(1.0-13.9)$ & NS \\
\hline Secondary immune response & $5.3(1.4-20.8)$ & $3.9(1.04-14.5)$ & $5.1(1.4-17.7)$ & $5.6(1.7-19.2)$ \\
\hline Increased LDH & $4.9(0.6-107.0)$ & NS & Undefined & NS \\
\hline
\end{tabular}

1094 - JID 2007:195 (15 April) - Wichmann et al. 
ing in our population. However, patients with spontaneous bleeding or other severe clinical manifestation had significantly lower median platelet counts.

The definition of severe dengue disease is not uniform among published studies. In a study of adults in Nicaragua $[25,26]$, severe disease was defined by the presence of at least 1 of 4 clinical signs. In our series, $11 \%$ of patients had at least 1 of those features. However, it must be taken into account that our patients were recruited at outpatient departments and clinics of specialized institutions only. Therefore, travelers with asymptomatic infections or mild disease are often missed, which leads to an artificially high rate of severe manifestations.

Median serum levels of both AST and ALT were higher in patients with spontaneous bleeding and other severe manifestations. In multivariate analysis, AST levels increased by $>3$ fold were independently associated with severe manifestations, and ALT levels increased by $>3$-fold with spontaneous bleeding. Previous publications have suggested that increased liver enzymes could be used as an indicator for disease severity [40]. The first published fatal case of travel-acquired dengue infection was complicated by fulminant hepatic failure [14]. It has to be pointed out, however, that there was a great range in the laboratory values, which limits their predictive value as markers for bleeding or severe disease in single patients. In addition, the time of blood collection must be taken into account: Although most abnormal platelet and WBC values were found between 3 and 6 days after the onset of symptoms, most highly increased liver enzyme levels were found later during the course of disease.

Preexisting dengue antibodies were the most significant risk factor for both spontaneous bleeding and other severe dengue manifestations. This is supported by a previously published observation, in which travelers of non-European origin had a 4 -fold higher risk of developing DHF [20]. However, not all severe cases can be explained by this: $50 \%$ of our patients with bleeding or other severe manifestations demonstrated a primary immune response, which is underlined by the fact that $30 \%$ of them visited dengue-endemic areas for the first time. Nonetheless, these findings emphasize the need for more-stringent protection against mosquito bites for travelers with previous dengue infections or of non-European origin, as well as a careful evaluation and follow-up of such patients who return home sick after visiting a country in which dengue is endemic.

\section{Acknowledgments}

We thank all site staff, who have been invaluable locally in managing the patients and collecting the data; and Dr. C. Domingo (Instituto de Salud Carlos III, Madrid, Spain), who performed polymerase chain reaction testing on a subgroup of the samples.

\section{References}

1. Wilder-Smith A, Schwartz E. Dengue in travelers. N Engl J Med 2005; 353:924-32.

2. Freedman DO, Weld LH, Kozarsky PE, et al. Spectrum of disease and relation to place of exposure among ill returned travelers. $\mathrm{N}$ Engl J Med 2006; 354:119-30.

3. Gubler DJ. Epidemic dengue/dengue hemorrhagic fever as a public health, social and economic problem in the 21st century. Trends Microbiol 2002; 10:100-3.

4. Gibbons RV, Vaughn DW. Dengue: an escalating problem. BMJ 2002; 324:1563-6.

5. Fakeeh M, Zaki AM. Virologic and serologic surveillance for dengue fever in Jeddah, Saudi Arabia, 1994-1999. Am J Trop Med Hyg 2001;65: 764-7.

6. Reiter P, Lathrop S, Bunning M, et al. Texas lifestyle limits transmission of dengue virus. Emerg Infect Dis 2003; 9:86-9.

7. Effler PV, Pang L, Kitsutani P, et al. Dengue fever, Hawaii, 2001-2002. Emerg Infect Dis 2005; 11:742-9.

8. World Tourism Organization (UNWTO). UNWTO NEWS. Madrid: UNWTO. Available at: http://www.world-tourism.org/newsroom/ magazine/archives/news1_06_e.pdf. Accessed 20 February 2007.

9. Cobelens FG, Groen J, Osterhaus AD, Leentvaar-Kuipers A, Wertheimvan Dillen PM, Kager PA. Incidence and risk factors of probable dengue virus infection among Dutch travellers to Asia. Trop Med Int Health 2002; 7:331-8.

10. Guzman MG, Kouri G. Dengue: an update. Lancet Infect Dis 2002; 2: $33-4$.

11. Halstead SB. Pathogenesis of dengue: challenges to molecular biology. Science $1988 ; 239: 476-81$.

12. Rigau-Perez JG, Laufer MK. Dengue-related deaths in Puerto Rico, 1992-1996: diagnosis and clinical alarm signals. Clin Infect Dis 2006;42: $1241-6$.

13. Halstead SB. Dengue. Curr Opin Infect Dis 2002; 15:471-6.

14. Lawn SD, Tilley R, Lloyd G, et al. Dengue hemorrhagic fever with fulminant hepatic failure in an immigrant returning to Bangladesh. Clin Infect Dis 2003;37:e1-4.

15. Jensenius M, Berild D, Ormaasen V, Mæhlen J, Lindegren G, Falk KI. Fatal subarachnoidal haemorrhage in a Norwegian traveler with dengue virus infection. Scand J Infect Dis 2007;39:272-4.

16. Nilsson J, Vene S, Mattsson L. Dengue encephalitis in a Swedish traveller returning from Thailand. Scand J Infect Dis 2005; 37:776-8.

17. Haritoglou C, Dotse SD, Rudolph G, Stephan CM, Thurau SR, Klauss V. A tourist with dengue fever and visual loss. Lancet 2002; 360:1070.

18. López-Vélez R, Pérez-Casas C, Vorndam AV, Rigau J. Dengue in Spanish travelers returning from the tropics. Eur J Clin Microbiol Infect Dis 1996; 15:823-6.

19. Centers for Disease Control and Prevention (CDC). Travel-associated dengue-United States, 2005. MMWR Morb Mortal Wkly Rep 2006; 55:700-2.

20. Wichmann O, Mühlberger N, Jelinek T. Dengue-the underestimated risk in travellers. Dengue Bull 2003;27:126-37.

21. Centers for Disease Control and Prevention. Travel-associated dengue infections-United States, 2001-2004. MMWR Morb Mortal Wkly Rep 2005; 54:556-8.

22. Jelinek T, Muhlberger N, Harms G, et al. Epidemiology and clinical features of imported dengue fever in Europe: sentinel surveillance data from TropNetEurop. Clin Infect Dis 2002; 35:1047-52.

23. World Health Organization (WHO). Dengue haemorrhagic fever: diagnosis, treatment, prevention and control. 2nd ed. Geneva: WHO, 1997.

24. Domingo C, Palacios G, Jabado O, et al. Use of a fragment of the Cterminal $\mathrm{E}$ gene for detection and characterization of two new lineages of dengue virus 1 in India. J Clin Microbiol 2006; 44:1519-29.

25. Balmaseda A, Hammond SN, Perez MA, et al. Assessment of the World 
Health Organization scheme for classification of dengue severity In Nicaragua. Am J Trop Med Hyg 2005; 73:1059-62.

26. Hammond SN, Balmaseda A, Perez L, et al. Differences in dengue severity in infants, children, and adults in a 3-year hospital-based study in Nicaragua. Am J Trop Med Hyg 2005; 73:1063-70.

27. Frank C, Schoneberg I, Krause G, Claus H, Ammon A, Stark K. Increase in imported dengue, Germany, 2001-2002. Emerg Infect Dis 2004; 10: 903-6.

28. Lindback H, Lindback J, Tegnell A, Janzon R, Vene S, Ekdahl K. Dengue fever in travelers to the tropics, 1998 and 1999. Emerg Infect Dis 2003;9: 438-42.

29. Cao XT, Ngo TN, Wills B, et al. Evaluation of the World Health Organization standard tourniquet test and a modified tourniquet test in the diagnosis of dengue infection in Viet Nam. Trop Med Int Health 2002; 7:125-32.

30. Wichmann O, Hongsiriwon S, Bowonwatanuwong C, Chotivanich K, Sukthana Y, Pukrittayakamee S. Risk factors and clinical features associated with severe dengue infection in adults and children during the 2001 epidemic in Chonburi, Thailand. Trop Med Int Health 2004;9: $1022-9$.

31. Innis BL, Nisalak A, Nimmannitya $S$, et al. An enzyme-linked immunosorbent assay to characterize dengue infections where dengue and Japanese encephalitis co-circulate. Am J Trop Med Hyg 1989; 40: 418-27.

32. Vaughn DW, Nisalak A, Solomon T, et al. Rapid serologic diagnosis of dengue virus infection using a commercial capture ELISA that distinguishes primary and secondary infections. Am J Trop Med Hyg 1999; 60:693-8

33. Schwartz E, Mileguir F, Grossman Z, Mendelson E. Evaluation of ELISA-based sero-diagnosis of dengue fever in travelers. J Clin Virol 2000; 19:169-73.

34. Chan DP, Teoh SC, Tan CS, et al. Ophthalmic complications of dengue. Emerg Infect Dis 2006; 12:285-9.

35. Wiwanitkit V. Dengue myocarditis, rare but not fatal manifestation. Int J Cardiol 2006; 112:122.

36. Horta Veloso H, Ferreira JA Jr, et al. Acute atrial fibrillation during dengue hemorrhagic fever. Braz J Infect Dis 2003; 7:418-22.

37. Shepard DS, Suaya JA, Halstead SB, et al. Cost-effectiveness of a pediatric dengue vaccine. Vaccine 2004; 22:1275-80.

38. Phuong CX, Nhan NT, Kneen R, et al. Clinical diagnosis and assessment of severity of confirmed dengue infections in Vietnamese children: is the World Health Organization classification system helpful? Am J Trop Med Hyg 2004; 70:172-9.

39. Rigau-Perez JG. Severe dengue: the need for new case definitions. Lancet Infect Dis 2006; 6:297-302.

40. Murgue B, Deparis X, Chungue E, Cassar O, Roche C. Dengue: an evaluation of dengue severity in French Polynesia based on an analysis of 403 laboratory-confirmed cases. Trop Med Int Health 1999; 4:765-73.

41. Deen JL, Harris E, Wills B, et al. The WHO dengue classification and case definitions: time for a reassessment. Lancet 2006;368;170-3. 